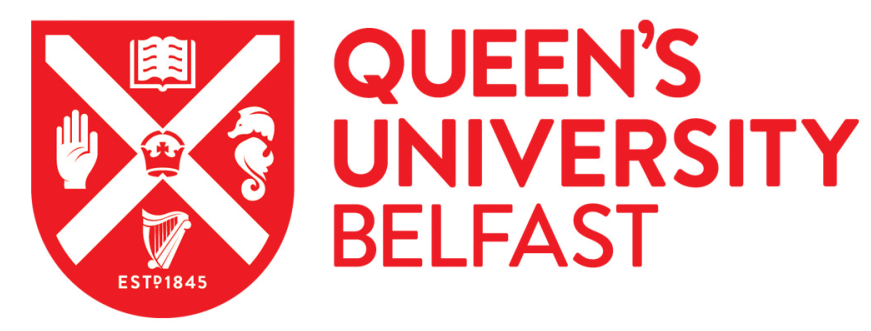

\title{
The effects of rosiglitazone on the neonatal rat cardiomyocyte transcriptome: a temporal analysis
}

\author{
da Silveira, W. A., Vazquez-Hidalgo, E., Bartolotta, E., Renaud, L., Paolini, P., \& Hardiman, G. (2019). The \\ effects of rosiglitazone on the neonatal rat cardiomyocyte transcriptome: a temporal analysis. \\ Pharmacogenomics, 20(16), 1125-1141. https://doi.org/10.2217/pgs-2019-0077
}

\section{Published in:}

Pharmacogenomics

\section{Document Version:}

Peer reviewed version

\section{Queen's University Belfast - Research Portal:}

Link to publication record in Queen's University Belfast Research Portal

\section{Publisher rights}

(C) 2019 Future Medicine. This work is made available online in accordance with the publisher's policies. Please refer to any applicable terms of use of the publisher.

\section{General rights}

Copyright for the publications made accessible via the Queen's University Belfast Research Portal is retained by the author(s) and / or other copyright owners and it is a condition of accessing these publications that users recognise and abide by the legal requirements associated with these rights.

Take down policy

The Research Portal is Queen's institutional repository that provides access to Queen's research output. Every effort has been made to ensure that content in the Research Portal does not infringe any person's rights, or applicable UK laws. If you discover content in the Research Portal that you believe breaches copyright or violates any law, please contact openaccess@qub.ac.uk. 
The effects of rosiglitazone on the neonatal rat cardiomyocyte transcriptome: a temporal analysis

Willian Abraham da Silveira ${ }^{1,2}$, Esteban Vazquez-Hidalgo ${ }^{3,4}$, Elesha Bartolotta ${ }^{3}$, Ludivine Renaud ${ }^{1,5}$, Paul Paolini ${ }^{*}, 3,4$ \& Gary Hardiman ${ }^{* *, 1,2,5}$

${ }^{1}$ Center for Genomic Medicine, Bioinformatics, Medical University of South Carolina, Charleston, SC, USA

${ }^{2}$ Faculty of Medicine, Health \& Life Sciences, School of Biological Sciences, Institute for Global Food Security (IGFS), Belfast, Northern Ireland, UK

${ }^{3}$ Department of Biology, San Diego State University, San Diego, CA, USA

${ }^{4}$ Computational Science Research Center, San Diego State University, San Diego, CA, USA

${ }^{5}$ Department of Medicine, Medical University of South Carolina, Charleston, SC, USA

*Authors for correspondence: ppaolini@mail.sdsu.edu

**Authors for correspondence: G.Hardiman@qub.ac.uk

\section{Abstract}

Aim: The objective was to determine via high-throughput RNA sequencing the temporal effects of rosiglitazone (AvandiaR ) on the neonatal rat ventricular myocyte transcriptome. Materials \& methods: Neonatal rat ventricular myocytes (NRVMs) were exposed to rosiglitazone in vitro. Meta analyses utilized temporal comparisons of $0.5 \mathrm{~h}$ control versus $0.5 \mathrm{~h}$ treatment, $0.5 \mathrm{~h}$ treatment versus $24 \mathrm{~h}$ treatment and $24 \mathrm{~h}$ treatment versus $48 \mathrm{~h}$ treatment. Results: Time dependent responses were observed. At $0.5 \mathrm{~h}$, the PI3KAKT signaling pathway was impacted. At $24 \mathrm{~h}$ endoplasmic reticulum activity and protein degradation were altered. At $48 \mathrm{~h}$, oxytocin signaling was perturbed. Conclusion: The effects of rosiglitazone occurred early and increased in magnitude over time. A protective molecular response was triggered at $24 \mathrm{~h}$ and maintained until $48 \mathrm{~h}$. In parallel, a response that can cause cardiac damage was activated. Our findings suggest that rosiglitazone has deleterious effects.

\section{Graphical Abstract:}

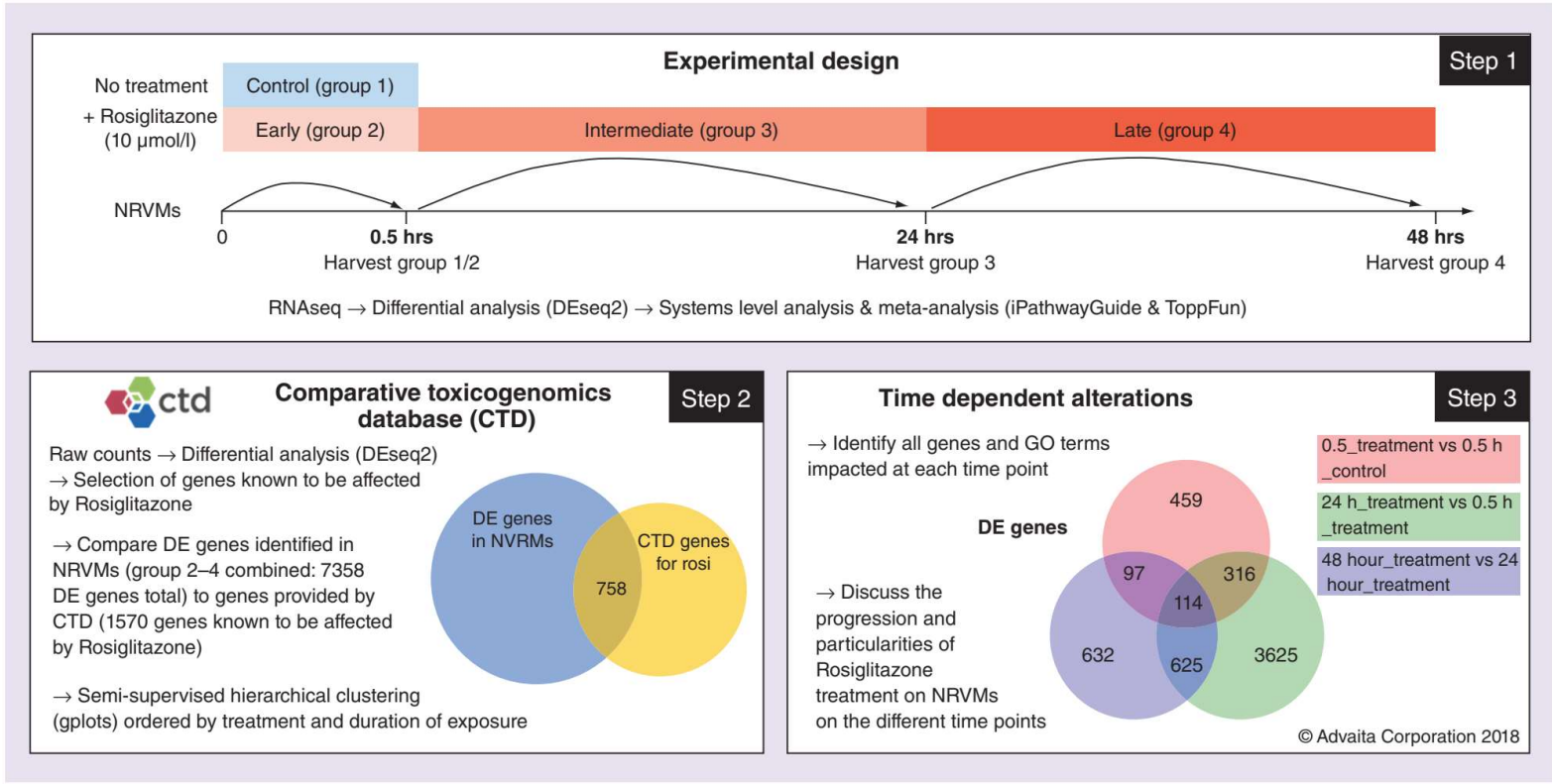


Keywords: AvandiaR $\bullet$ neonatal rat ventricular myocytes $\bullet$ peroxisome proliferator-activated receptor-gamma $\bullet$ RNAseq $\bullet$ rosiglitazone $\bullet$ Type 2 diabetes mellitus

\section{Introduction}

Rosiglitazone is ananti-diabetic treatment member of the thiazolidinedione (TZD) drug class. TZDs are ligands and selective agonists of the peroxisome proliferation activating receptor $\gamma$ (PPAR $\gamma$ ), a nuclear hormone receptor intricately involved in the regulation of genes related to glucose and lipid metabolism [1]. One of the main effects of rosiglitazone is to act as an insulin sensitizer, increasing by $30-50 \%$, the cellular uptake of glucose mediated by insulin and reducing glucose production [13]. Although PPARy is expressed principally in adipose tissue, it is also present in several other cell types (cardiac, skeletal, smooth muscle, islet $\beta$ cells, vascular endothelial cells and macrophages) leading to complex effects on a wide variety of tissues $[1,4]$.

The use of rosiglitazone has been shown to increase the risk of congestive heart failure in Type 2 diabetes patients due to increased fluid retention and plasma volume $[1,3,5]$. Other characterized side effects include weight gain, liver complications, anemia, tiredness and bone fractures $[1,3,5]$. Consequently, the use of rosiglitazone has been restricted in the USA and prohibited in the European Union [3]. Despite these potential risks, rosiglitazone has enjoyed commercial success and provided beneficial therapeutic effects to a subpopulation of patients with Type 2 diabetes [6,7]. It has also been used as an adjuvant or principal treatment for other diseases such as prostate cancer, malaria, ulcerative colitis, schizophrenia, Alzheimer's disease and depression [8-13]. These applications highlight the need to clearly define rosiglitazone's mode of action, its therapeutic benefits as well as its safety and side effects.

The traditional paradigm in cardiology is that cardiomyocytes $(\mathrm{CM})$ are terminally differentiated (i.e., cannot be recalled into the cell cycle) and that the human adult heart lacks regenerative capacity following insult, leading to the replacement of necrotic muscle tissue by fibrotic scar tissue after cardiac injury and the loss of contractility that can culminate in heart failure and death [14]. Recent studies, however, have put forward new evidence for adult cardiogenesis in mammals including humans [14-16]. It has been demonstrated both in vitro and in vivo that mature adult CM, influenced by neighbor cells and calcium signaling, can re-enter the cell cycle and form new CM through a three-step process: dedifferentiation, proliferation and redifferentiation [17]. Interestingly, the neonatal mouse heart has a robust regenerative capacity in the first seven postnatal days [18]; a process that is dependent of an early inflammatory response [14]. Another murine model widely used in heart disease research are neonatal rat ventricular myocytes (NRVMs) $[14,19]$ which provide an excellent tool to evaluate the effect of rosiglitazone on cardiac molecular 
functions.

Our group previously explored the temporal effects associated with exposure to the drug using NRVMs and DNA microarray technology. We stratified the dataset into three different stages, representing immediate, intermediate and late gene expression profiles and carried out gene ontology analyses. This approach demonstrated the effects of rosiglitazone on the 'development of cardiovascular system', 'extracellular matrix' and 'immune response' biological pathways were dependent on exposure length to the drug [19], suggesting that the deleterious effects of rosiglitazone on the heart go beyond fluid retention and that the molecule has direct effects on heart cells.

The aim of this subsequent study was to exploit the same model and analytic approach to determine the effects of $10 \mu \mathrm{mol} / /$ rosiglitazone treatment on NRVMs after specific exposure times of $0.5,24$ and 48 hours via highthroughput RNA sequencing coupled to temporal gene expression level analyses. The rationale for the single dose selection in these experiments was based on cost considerations, and the fact that previous work has indicated cardioprotective effects of the drug at (10 $\mu \mathrm{mol} / \mathrm{I})$ [20]. We sought to expand current knowledge of the mechanisms of action of rosiglitazone and gain insights into the potential temporal side effects that may occur with therapeutic administration in patients.

\section{Materials \& methods}

\section{Animals, cell culture, RNA extraction \& sequencing}

All animal procedures were in accordance with the San Diego State University Animal Subjects Committee and NIH Animal Welfare Assurance A3728-01. NRVMs were harvested from 1-day old Harlan Sprague-Dawley rats (Rattus norvegicus albinus) and cultured as previously described [20]. Preplating isolated cells to remove fibroblasts yielded $>98 \%$ NRVMs. Cell count was determined after preplating. Pooled NRVMs were centrifuged and resuspended in $20 \mathrm{ml} \mathrm{DMEM/F-12} \mathrm{(Gibco,} \mathrm{Life}$ Technologies, CA, USA) with 10\% fetal bovine serum (Irvine Scientific, CA, USA) and quantified via hemacytometer. NRVMs were plated on Fibronectin (Gibco)-coated $35 \mathrm{~mm}$ dishes and incubated overnight to allow for recovery. On the following day, NRVMs were washed twice with 1:1 medium DMEM/F-12, kanamycin, ampicillin and fungizone. NRVMs were incubated overnight in minimal medium consisting of $1: 1$ medium with $1 \mathrm{mg} / \mathrm{ml}$ bovine serum albumin (Sigma, MO, USA). On the third day, cells were washed twice with 1:1 medium. Minimal medium was replaced with insulintransferrin selenium medium consisting of minimal medium, 1X insulin-transferrin-selenium (Life Technologies, CA, USA), 0.4X MEM nonessential amino acids mixture (Sigma), and 0.1X MEM vitamins medium (Invitrogen, CA, USA). The control group was supplemented with $1 \%$ DMSO, and 
the experimental group was supplemented with $10 \mu \mathrm{mol} / /$ rosiglitazone (Sigma-Aldrich) and $1 \%$ DMSO. NRVMs were exposed to control and experimental conditions for $0.5,24$ and $48 \mathrm{~h}$. The concentration of rosiglitazone $(10 \mu \mathrm{mol} / \mathrm{l})$ and time points were selected based on previous work from this group $[19,20]$. For the $0.5 \mathrm{~h}$ control, two technical replicates were included. For each other time point and condition, two independent biological and two technical replicates of each biological control were included respectively (i.e., four total replicates).

After the appropriate exposure time, isolation of total RNA for RNA sequencing from NRVMs was performed using RNeasy Mini Kit (Qiagen) as per the manufacturer's protocol. RNA purity was determined by spectrophotometry using a NanoDrop 2000 (Thermo Scientific). Ratios of 260/280 and 260/230 were approximately 2.0. Further, RNA purity validation and RNA sequencing was conducted by the Sanford Burnham Prebys Genomic Core in La Jolla, CA, USA. RNA integrity was verified using RNA 6000 Nano Assay chips run in Agilent 2100 Bioanalyzer (Agilent Technologies, CA, USA). PolyA RNA was isolated using the NEBNextR Poly(A) mRNA Magnetic Isolation Module and barcoded libraries were made using the NEBNextR Ultra IIM Directional RNA Library Prep Kit for IlluminaR (NEB, MA, USA). Libraries were pooled and single end sequenced (1X75) on an Illumina NextSeq 500 using the High output V2 kit (Illumina Inc., CA, USA).

\section{RNAseq analysis}

Secondary data analysis was performed on an OnRamp Bioinformatics Genomics Research Platform (OnRamp Bioinformatics, CA, USA). This advanced genomics analysis engine utilized an automated RNAseq workflow, including data validation and quality control, read alignment to the Rattus novergicus genome (Rnor 6.0) using STAR RNA-seq aligner, generation of gene-level count data with HTSeq and differential expression analysis with DEseq2, which enabled the inference of differential signals with robust statistical power [21-23]. The resulting SAM files from the alignment step were sorted and inputted into the Python package HTSeq to generate count data for gene-level differential expression analyses [24].

\section{Temporal analysis using complete transcriptome analysis}

Using the strategy, we successfully exploited in our previous study using microarray data where we assessed 11 longitudinal time points from 0.5 to $48 \mathrm{~h}$ [19]; the RNAseq data were divided into four groups: $0.5 \mathrm{~h}$ with no treatment, $0.5 \mathrm{~h}$ with treatment, $24 \mathrm{~h}$ with treatment and $48 \mathrm{~h}$ with treatment. In order to assess temporal effects, we made time series comparisons with $0.5 \mathrm{~h}$ no treatment versus $0.5 \mathrm{~h}$ treatment, $0.5 \mathrm{~h}$ treatment versus $24 \mathrm{~h}$ treatment and $24 \mathrm{~h}$ treatment versus $48 \mathrm{~h}$ treatment, which we defined as early, medium and late exposures. In order to infer differential 
signal within the datasets with robust statistical power, we utilized DESeq2. Log2 foldchange (log2FC) estimation and hypothesis testing for differential expression were performed using the DESeq2 Bioconductor library. For each gene, DESeq2 reported an estimated log2FC, and provided an adjusted $p$ value (or q value) equivalent to the smallest false discovery rate (FDR) incurred when declaring that test significant $[21,22]$. FDR is the expected fraction of false positive tests among significant tests and was calculated using the Benjamini-Hochberg multiple testing adjustment procedure [25]. Transcript count data from DESeq2 analysis of the samples were sorted according to their q value.

The differentially expressed (DE) lists derived from complete transcriptome analysis were then interrogated

using iPathwayGuide tool from AdvaitaR Bioinformatics. This tool uses a systems biology approach in order to

identify pathways that are significantly impacted in any condition from high-throughput gene expression data. The impact analysis incorporates the classical probabilistic component of the magnitude of the expression changes of each gene; the position of the DE genes on the given pathways, the topology of the pathway that describes how these genes interact and the type of signaling interactions between them [26]. iPathwayGuide was used to perform a meta-analysis across the early, medium and late exposures. This allowed us to identify genes, pathways and GO terms that were common or unique across these early, medium and late stages.

In addition, these DE gene lists derived from complete transcriptome analysis were interrogated using the ToppGene Suite functional enrichment tool [27]. The RNAseq dataset was deposited into the GEO repository under the accession number GSE117198.

\section{Temporal analysis of Comparative Toxicogenomics Database genes impacted by rosiglitazone}

Raw counts were normalized by the variance stabilizing transformation method using DESeq2 (version 1.16.1). These normalized data were first annotated to human orthologues and then filtered to contain only genes known to be affected by rosiglitazone as determined by the Comparative Toxicogenomics Database (CTD) [28] and that were recognized as DE in at least one of the comparisons. Semi-supervised hierarchical clustering was performed to cluster the genes using gplots (version 3.0.1) with default parameters. Utilizing the clustering patterns, the data were subsequently ordered sequentially with regard to the treatment and duration of exposure.

\section{Quantitative real-time PCR analysis}


Three transcripts were selected for real-time quantitative RT-PCR (q-PCR) CYP450, family 1, subfamily b, polypeptide 1 (Cyp1b1), NAD(P)H dehydrogenase, quinone 1 (Nqo1), mRNA and angiopoietin-like 4 (Angpt/4). Intron spanning assays were designed for all three mRNA targets (Supplementary Table 10), and mRNA transcript levels were measured by in a LightCycler 480 (Roche Applied Science, IN, USA) using SYBR Green quantitative PCR. A separate biological experiment with the same time course data points described above was carried out. Total RNA was extracted from the $\mathrm{CM}$ and reverse-transcribed using the Roche Transcriptor kit and 50 ng CDNA were quantified using LightCycler 480 SYBR Green Master Kit. We assessed amplification and melting curves for each of these targeted assays. Dissociation curves were run following the RT-PCR. Careful analysis of all dissociation curves was subsequently performed to ensure that the desired amplicons were detected, and primer-dimer products and contaminating and nonspecific amplicons were not providing additional signal. The derivative melting curve is generally the most informative for performing quality control of the assays. We plotted the negative first derivative of the meltingcurve data to determine whether specific peaks were present or not. The GAPDH transcript using the murine probe 480 (Roche Applied Science) was used as an internal control for normalization. Normalized gene expression values were obtained using LightCycler Relative Quantification software (Roche). Each sample was run in duplicate and mean values were reported. Relative gene copy numbers were derived using the formula for $2 \mathrm{CT}$ where $\mathrm{CT}$ is the difference in amplification cycles required to detect amplification product from equal starting concentrations of cardiomyocyte RNA. We used the following formula for analyzing the q-PCR data

$$
\frac{E_{g}^{C p_{g}(C)-C p_{g}(T)}}{E_{r}^{C p_{r}(C)-C p_{r}(T)}}
$$

where $g$ represents a gene of interest, $r$ is the reference 'housekeeping' gene, Eg and Er are the efficiencies of gene and reference gene cycling respectively, and $C$ and $T$ are the control and test samples respectively being compared. Data presented here are in the form of mean values and in the form of expression change by contrast to be consistent with the RNAseq data analysis.

\section{Results}

\section{Effects of rosiglitazone on known affected genes - comparison with the Comparative Toxicogenomics Database}

The samples in the dataset contains on average 18,203,318 reads each, with an average rate of uniquely mapped reads of $82.97 \%$. Using the q-value threshold of $\leq 0.01$, the analysis uncovered 986 $\mathrm{DE}$ genes in the comparison of $0.5 \mathrm{~h}$ no treatment versus $0.5 \mathrm{~h}$ treatment, 4,680 DE genes in the comparison $0.5 \mathrm{~h}$ treatment versus $24 \mathrm{~h}$ treatment and 1,468 DE genes in the comparison $24 \mathrm{~h}$ 
treatment versus $48 \mathrm{~h}$ treatment. To evaluate if the gene expression patterns, we observed were in agreement with what is known to date for rosiglitazone exposure we compared our results with the CTD. The CTD contains manually curated information about chemical-gene/- protein interactions, chemical-disease and gene-disease relationships for many chemicals including rosiglitazone. By comparing our list of DE genes obtained across all three time points examined (7,358 DE genes in total), to the 1,570 genes that are known to be affected by rosiglitazone [28], we noted that our analysis captured $43.06 \%$ of the CTD list as DE genes in our rat NRVM model (Supplementary Figure 1 \& Supplementary Table 1). We encountered 68,245 and 78 upregulated CTD genes and 99,277 and 123 downregulated CTD genes at the early, medium and late time points, respectively (Figure 1). Complete mapping data, which provides metrics on the number of total input reads, uniquely mapped reads and percentage uniquely mapped reads, are provided as Supplementary Figure 2.

\section{Temporal analysis of DE genes in response to rosiglitazone}

Using the totality of CTD DE genes at the medium and later time points compared with the early time point with no treatment, a temporal analysis of the gene expression patterns (Tables 1-4 \& Supplementary Tables $2 \& 3$ ) showed that in healthy rat $\mathrm{CM}$, in other words, those with normal levels of glucose and insulin response, rosiglitazone upregulated genes related to PPAR signaling pathways and fatty acid metabolism (Table 1), and genes related to mouse phenotypes linked to metabolism and metabolic disorders as determined from the International Mouse Phenotyping Consortium (IMPC) database (Table 2). The mouse phenotype was chosen because of the evolutionary relationship between mice and rats and the IMPC rich content. This treatment downregulated transcripts from pathways related to stress and atherosclerosis, advanced glycation end products, extracellular matrix and immune response (Table 3) as well as transcripts signatures present in mouse phenotypes related to muscle and cardiovascular physiology (Table 4).

Once we established that our findings were in agreement with the literature, we explored the complete set of DE genes to exploit the time dependency of mRNA DE and to explore potentially relevant but still undocumented genes and pathway alterations in the context of rosiglitazone exposure. A meta-analysis was carried out across the early, medium and late exposures, which allowed us to identify genes, pathways and GO terms, that were common or unique across these early, medium and late stages. It is interesting to note that although the number of differentially expressed genes grows considerably from $30 \mathrm{~min}$ to $24 \mathrm{~h}$ exposure, 986 to 4,680 DE genes, and $1,468 \mathrm{DE}$ genes from $24 \mathrm{~h}$ to $48 \mathrm{~h}$ exposure (Figure 2 \& Supplementary Table 4), the great majority of gene ontology terms were impacted during the first 30 min with $86.3 \%(1222 / 1416)$ of biological process terms, $97.2 \%$ (70/72) molecular function terms and $71.7 \%(104 / 145)$ of the cellular 
component terms (Figure 2B \& Supplementary Tables $5-7$ ). This demonstrates that at a systems level, the transcriptomic response to rosiglitazone occurs rapidly and increases in intensity over time.

Similarly, key pathways were activated in a temporal manner (Supplementary Table 8). For example, the early response includes the PI3K-AKT signaling pathway, specifically the genes phosphoinositide3-kinase regulatory subunit 5 and phosphatidylinositol-4,5-bisphosphate 3-kinase catalytic subunit $\beta$ (Pik3rs and PiK3cb, respectively) were downregulated and maintained at low levels during the duration of the experiment (Figure $3 \mathrm{~A}$ ). The early exposure time point also revealed downregulated genes in pathways related to immune function as exemplified by the downregulation of Tnfaip8/2, Tnfrsf1b and Tnfrsf21 (Supplementary Table 4), and altered calcium ion homeostasis (Figure 3B \& C). At the middle time point, we detected an alteration in the protein processing and endoplasmic reticulum (Figure 4A), and proteosome pathways (Figure 4B) with the upregulation of 102 genes out of a total of 127 genes belonging to the proteasome-mediated ubiquitin-dependent protein catabolic process GO term (Figure 4C). The unfolded protein response (UPR), is also a pathway significantly impacted $24 \mathrm{~h}$ after exposure $(q=0.02)$, Supplementary Table 8 . It is of note to cite the differential expression of the hypoxia inducible factor $3 \alpha$ subunit $(H I F 3 A, \log 2 F C=-2.371, q=0.002$ ) at this time point. At the later time point, we observed the downregulation of the oxytocin signaling pathway (Figure 5A), alteration in the osteoclast differentiation pathway with up- and downregulated genes (Figure 5B), and 12 downregulated genes out of 14 DE genes related to the regulation of the force of heart contraction pathway (Figure $5 C$ ), including the upregulation of HIF1A $(\log 2 \mathrm{FC}=+1.530, \mathrm{q}=7.593 \mathrm{e} 4)$.

\section{Quantitative real-time PCR analysis of selected mRNA targets}

We chose three transcripts for real-time quantitative RT-PCR (q-PCR) validation, Cyp1b1, Nqo1, and Angpt/4. The rationale for selecting these three mRNAs were that the RNAseq data indicated that all three transcripts followed a temporal pattern of gene expression, and all three were highly significant DE $(q<0.1)$ in two of the RNAseq time point comparisons. Comparisons of the $0.5 \mathrm{~h}$ no treatment versus $0.5 \mathrm{~h}$ treatment revealed modest downregulation of all three transcripts in the drug exposed relative to the control. Comparison of the $0.5 \mathrm{~h}$ treatment versus $24 \mathrm{~h}$ treatment revealed a strong upregulation of these transcripts in the $24 \mathrm{~h}$ treated sample. Finally comparison of the $24 \mathrm{~h}$ treatment versus $48 \mathrm{~h}$ treatment revealed a modest upregulation in the $48 \mathrm{~h}$ relative to the $24 \mathrm{~h}$ indicating that these transcripts continue to be overexpressed as the time course continues (Supplementary Figures 3-5A). A separate time course experiment was set up to assess the data via q-PCR at the same time points. This revealed that Cyp1b1, Nqo1 and Angpt/4 exhibited comparable 
patterns of expression in the early, medium and late exposure comparisons using q-PCR and in a different biological replicate experiment (Supplementary Figures 3-5B).

\section{Discussion}

Our previous work demonstrated an alteration in the extracellular matrix-remodeling processes in rosiglitazoneexposed CM [19], which is in agreement with recent findings showing that rosiglitazone attenuates cardiac fibrosis $[29,30]$, suggesting that the drug could play a protective role in the heart. However, the use of rosiglitazone in Type 2 diabetes patients has been shown to 1 ) increase the risk of heart failure in the majority of patients within a few months or within years after initiating the treatment, 2) be beneficial with no side effects in a subpopulation of patients that will never develop heart diseases [31], highlighting that there are not only genetic and environmental influences associated with this drug, but also a temporal effect. In this study, we examined the temporal nature of the transcriptomic response to rosiglitazone over a time span of $48 \mathrm{~h}$. First, we focused on the expected gene expression response to test if our model was valid and then on possible mechanisms that could potentially lead to heart injury. These time series experiments provided an opportunity to observe the emergence of coherent responses with many interacting components, and to characterize the transitory state of this system by identifying the activated pathways individually and exploring their interconnectivity [32].

Using a list of genes known to be affected by rosiglitazone from CTD [28] we carefully evaluated the temporal response. Although changes in rat NRVM gene expression were altered during the first 30 min following treatment, the intensity of the response grew in magnitude during the first $24 \mathrm{~h}$ and was maintained in a plateau until $48 \mathrm{~h}$. Upregulated pathways and signatures related to enriched phenotypes in mouse included PPAR signaling, a known target of this drug [1]. Fatty acid metabolism and abnormal glucose homeostasis are additional pathways which are impacted and are in agreement with our previous findings [19]. Downregulated pathways and signatures related to mouse phenotypes included extracellular matrix organization, and IL-4 and IL-13. IL-4 and IL-13 are two anti-inflammatory cytokines with profibrotic properties, but also essential for myocardial homeostasis $[33,34]$, which explains the seemingly contradictory interplay between the antifibrotic properties of rosiglitazone and the increased risk of heart failure $[35,36]$. Mouse phenotypes linked to the cardiovascular system were also enriched and upregulated transcripts were associated with gene signatures associated with hepatic steatosis, abnormal glucose homeostasis, abnormal enzyme activity and abnormal metabolism. Downregulated transcripts were associated with abnormal cardiovascular and muscle physiology and morphology. Nonetheless, there are important time dependent responses to rosiglitazone. At $30 \mathrm{~min}$, the PI3K- 
AKT signalling pathway was altered; PI3Ks are master regulators of insulin action in the heart $[37,38]$. The interaction between insulin and PI3K is related to cardiac hypertrophic growth and increased cardiac contractility [38]. Consequently, deactivation of this system will negatively impact both processes. Also we reported downregulation of inflammatory pathways, including the chemokine signaling pathway. Inflammation may be protective in the early stages of myocardial infarction through stimulation of myocyte autophagy and anti-inflammatory drug therapy [39]. In particular, anti-TNF $\alpha$ therapy as an anti-inflammatory may adversely affect cardiac function [39]. Tnfaip8/2 was downregulated in our study, and has been shown to prolong the survival of rat allogeneic heart allografts [40].

We also reported early modulation of transcripts related to calcium ion homeostasis. Calcium fluxes are the most important ion currents underlying the process of contraction in cardiac, skeletal and smooth muscle [38] Dysregulation in Ca2+ fluxes is a hallmark of the development of cardiovascular diseases, altering the strength of cardiac muscle contraction and causing arrhythmias [38]. PI3K/Akt signaling plays an important role in the homeostatic regulation of $\mathrm{Ca} 2+$ in the cardiovascular system [38], and both signaling pathways are commonly simultaneously impacted [37,38,41]. Increasing levels of intracellular $\mathrm{Ca} 2+$ have been shown to decrease Akt protein concentration by less than half after $48 \mathrm{~h}$ [41], which concurs with an early change in expression patterns, considering that $A k t$ mRNA has a half-life of up to $24 \mathrm{~h}$ and that the Akt protein has a half-life close to $6 \mathrm{~h}[42,43]$. At $24 \mathrm{~h}$ after exposure to rosiglitazone, the CM presented a gene expression signature of a stress response with an increase in endoplasmic reticulum activity and at the same time an increase in protein degradation. The ER is an intracellular organelle essential for cellular homeostasis, development and stress responsiveness with demonstrated influences in the UPR, cellular metabolism of calcium and lipids and possible roles in the development of diabetes mellitus and cardiovascular diseases [44]. One of the main functions of the ER is the synthesis of proteins targeted to the secretory pathway, including a quality-control system that ensures that incompletely folded proteins are retained in the ER or targeted for degradation if appropriate folding cannot be achieved [44]. Calcium is an important ion for ER function, including protein processing, and the release of ER Ca2+ sufficient to impair protein processing promotes ER stress and triggers the UPR [45], a pathway impacted $24 \mathrm{~h}$ after exposure which suggests that the early alteration in calcium homeostasis could be contributing to the stress response which developed at $24 \mathrm{~h}$. The ubiquitin-proteasome system is the major nonlysosomal proteolytic system for the degradation of abnormal or damaged proteins, and has its highest activity in kidney and heart, indicating its importance in the health and disease states of these tissues [46]. Adult myocardial muscle cells are terminally differentiated with no reproductive potential [47] although mature adult CM were 
recently shown to possess some regenerative capability [17]. It is of extreme importance to maintain the viability of the cells in the adult heart, and proteasome activity plays a central role in removing damaged proteins and in maintaining energy production and sarcomere integrity [46]. A saturation of proteasome activity will result in abnormal protein deposition, leading to contractile dysfunction, inflammation and fibrosis, reduction of oxygen supply, apoptosis and necrosis [48]. Although rosiglitazone shows anti-inflammatory and antifibrotic properties $[19,20]$, possibly shielding the cells for these two processes, the downregulation of HIF3A has been shown to be cardioprotective [49]; this is consistent with the protective myocyte response we observed at $24 \mathrm{~h}$. The upregulation of HIF1A at $48 \mathrm{~h}$ could be an indication of a hypoxia-mediated response that is still developing. Oxytocin is a hormone produced in the heart that protects $\mathrm{CM}$ from apoptosis after an ischemia reperfusion insult [50]. At $48 \mathrm{~h}$ postexposure to rosiglitazone, the $\mathrm{CM}$ presented an overall downregulation of the oxytocin signaling pathway indicating further damage and stress at the cellular level. The alteration of gene expression in the osteoclast differentiation pathway can be an outcome of the alteration in calcium homeostasis indicative of myocyte induction by vascular calcification. Vascular calcification has been implicated in the development of heart failure [51]. It has been reported that cellular mediators of arterial mineral resorption are osteoclast like cells and net calcium deposition occurs as a result of focal perturbation of the balance between the activity of these cells [52]. Also, we encountered downregulation of genes related to the force of the heart contraction providing further indication of the decrease in function of $\mathrm{CM}$. Three transcripts that were identified as significant were Cyp1b1, Nqo1 and Angpt/4. We validated these using $\mathrm{q}-\mathrm{PCR}$ and $\mathrm{CM}$ from a separate biological replicate experiment to add confidence to the RNAseq results. Cyp1b1 belongs to the CYP450 superfamily of enzymes and functions in the metabolism and detoxification of toxic chemicals [53]. The function of CYP450 in cardiovascular disease is well known. Many CYP enzymes have been identified in the heart and their mRNA, and enzymatic levels (including CYP1B) have been reported to be increased during cardiac hypertrophy and heart failure [53]. ANGPTL4 plays a critical role in modulating cardiac substrate metabolism. It is activated by all PPAR family ligands [54]. Angpt/4 overexpression has been linked with detrimental effects on the heart. It is a potent inhibitor of lipoprotein lipase (LPL), regulating its activity in adipose, hepatic and cardiac tissue. In CM, LPL hydrolyses lipoproteins generating free fatty acids (FFA) which are oxidized to produce ATP [55]. As the heart is primarily dependent on lipoproteinderived FFA as its primary fuel source, loss of LPL-derived FFA by ANGPTL4 leads to cardiac dysfunction and impaired contractility [56]. NQO1 is a pleiotropic enzyme induced by multiple forms of stress including oxidative stress. It is protective against oxidative stress [57]. 
PGC-1 $\alpha$ coactivator plays a regulatory function in the maintenance of lipid balance via engagement in numerous metabolic processes. It provides a link between the import of fatty acids and their total oxidation or conversion into bioactive fractions through the coordination of both the expression and subcellular relocation of the proteins involved in the transmembrane movement of fatty acids $[58,59]$. Activation of PPARg in the heart results in an activation of PGC-1 $\alpha$ and subsequently mitochondrial biogenesis and stimulation of fatty acid oxidation. In our experiment, we observed modest upregulation of $P G C-1 \alpha$ in NRVMs at the $0.5 \mathrm{~h}$ no treatment versus $0.5 \mathrm{~h}$ treatment comparison. Comparison of the $0.5 \mathrm{~h}$ treatment versus $24 \mathrm{~h}$ treatment revealed a strong downregulation, which was maintained in the $24 \mathrm{~h}$ treatment versus $48 \mathrm{~h}$ treatment (Supplementary Figure 5). A disadvantage of our in vitro model compared with in vivo systems is that upon PPARg activation by rosiglitazone, $\mathrm{CM}$ need to burn more fatty acids and this cannot be achieved in vitro as the medium medium is supplied with high levels of glucose and insulin and does not contain fatty acids.

\section{Conclusion}

Overall, our data demonstrate that the effects of rosiglitazone on $\mathrm{CM}$ occur really early with increasing magnitude over time and consistently in the pathways affected. Also, the initial deleterious effect triggers a protective molecular response at $24 \mathrm{~h}$ following exposure that is maintained until $48 \mathrm{~h}$ but also accompanied by further activation of systems that can damage the heart. Overall, the use of rosiglitazone shows a propensity to be deleterious to the heart. Nonetheless, the experiments described here were performed in vitro (cell culture with primary cells) and it is not possible to infer exactly how much time is needed for the activation of these pathways to cause tissue and organ level alterations in the heart itself. It would be interesting to investigate further if patients that present with early rosiglitazone related side effects have a propensity to react negatively to stress in the pathways described here. The effect of rosiglitazone is mediated via activation of PPARg in the cardiomyocyte so one would anticipate similar effects from other TZDs. Future work will address other TZDs and will focus on animal models and integrate clinical data from early and late rosiglitazone adverse effects. As this study used short read sequencing $75 \mathrm{bp}$ reads, and this single end strategy does not permit a robust analysis of alternative splicing and mRNA isoforms that may be differentially regulated, this topic will be the subject of future work which will exploit long-read sequencing technologies.

\section{Executive summary}

Objective 
- Using high-throughput RNA sequencing and a temporal gene expression level analysis, determine the temporal effects of rosiglitazone (AvandiaR ) on the neonatal rat ventricular myocyte transcriptome.

- To better elucidate rosiglitazone's mode of action, understand its therapeutic benefits as well as its safety and side effects.

- To determine possible mechanisms by which rosiglitazone could potentially lead to heart injury.

\section{Approach}

- High-throughput RNA sequencing and temporal analyses were carried out to examine the effects of $10 \mu \mathrm{mol} / \mathrm{I}$ rosiglitazone treatment on a cardiomyocyte model after exposure times of $0.5,24$ and $48 \mathrm{~h}$ to the drug.

\section{Conclusion}

- Using a predefined list of genes affected by rosiglitazone from the Comparative Toxicogenomics Database allowed careful contextual evaluation of the temporal response.

- Subsequent analysis of the complete transcriptomics response indicated that the effects of rosiglitazone occur early and increase in magnitude with time. A protective molecular response is triggered at $24 \mathrm{~h}$ and maintained until $48 \mathrm{~h}$.

- In parallel a response that can cause cardiac damage is activated. Our findings suggest that rosiglitazone has deleterious effects.

\section{Financial \& competing interests disclosure}

Research in the Paolini Laboratory supported by a grant from the California Metabolic Research Foundation. The Hardiman laboratory acknowledges funding from SC EPSCOR and start-up funding from College of Medicine at the Medical University of South Carolina and Queen's University Belfast. GH acknowledges support from NIH 1U01DA045300-01A1. The authors have no other relevant affiliations or financial involvement with any organization or entity with a financial interest in or financial conflict with the subject matter or materials discussed in the manuscript apart from those disclosed. No writing assistance was utilized in the production of this manuscript.

\section{Ethical conduct of research}

The authors state that they have obtained appropriate institutional review board approval or have followed the principles outlined in the Declaration of Helsinki for all human or animal experimental investigations. 
1. Goodman LS, Brunton LL, Chabner B, Knollmann BC (Eds). Goodman \& Gilman's Pharmacological Basis of Therapeutics. McGraw-Hill, NY, USA (2011).

2. Yki-Jarvinen H. Thiazolidinediones. N. Engl. J. Med. 351(11), 1106-1118 (2004). 3. Yandrapalli S, Jolly G, Horblitt A, Sanaani A, Aronow WS. Cardiovascular benefits and safety of non-insulin medications used in the treatment of Type 2 diabetes mellitus. Postgrad. Med. 129(8), 811-821 (2017).

4. Ahmadian $M$, Suh JM, Hah $N$ et al. PPARgamma signaling and metabolism: the good, the bad and the future. Nat. Med. 19(5), 557-566 (2013).

5. (FDA) USFaDA.. Highlights of prescribing information: AVANDIAR (rosiglitazone maleate) tablets (2008). www.accessdata.fda.gov/drugsatfda docs/label/2008/021071s034lbl.pdf

6. Garg R, Gopal J, Jones GR. Rosiglitazone: safety and efficacy in combination with insulin in poorly controlled Type 2 diabetes mellitus patients treated with insulin alone. J. Diabetes Complications 21(1), 1-6 (2007).

7. Wang $\mathrm{CH}$, Leung $\mathrm{CH}$, Liu SC, Chung $\mathrm{CH}$. Safety and effectiveness of rosiglitazone in Type 2 diabetes patients with nonalcoholic fatty liver disease. J. Formos Med. Assoc. 105(9), 743-752 (2006).

8. Varo R, Crowley VM, Sitoe A et al. Safety and tolerability of adjunctive rosiglitazone treatment for children with uncomplicated malaria. Malar. J. 16(1), 215 (2017).

9. Qin L, Gong C, Chen AM et al. Peroxisome proliferatoractivated receptor gamma agonist rosiglitazone inhibits migration and invasion of prostate cancer cells through inhibition of the CXCR4/CXCL12 axis. Mol. Med. Rep. 10(2), 695-700 (2014).

10. Lewis JD, Lichtenstein GR, Deren JJ et al. Rosiglitazone for active ulcerative colitis: a randomized placebo-controlled trial. Gastroenterology 134(3), 688-695 (2008).

11. Mizuno Y, Suzuki T, Nakagawa A et al. Pharmacological strategies to counteract antipsychoticinduced weight gain and metabolic adverse effects in schizophrenia: a systematic review and metaanalysis. Schizophr. Bull. 40(6), 1385-1403 (2014).

12. Hsu WJ, Wildburger NC, Haidacher SJ et al. PPARgamma agonists rescue increased phosphorylation of FGF14 at S226 in the Tg2576 mouse model of Alzheimer's disease. Exp. Neurol. 295, 1-17 (2017).

13. Zhao Z, Zhang L, Guo XD et al. Rosiglitazone exerts an anti-depressive effect in unpredictable chronic mild-stress-induced depressive mice by maintaining essential neuron autophagy and inhibiting excessive astrocytic apoptosis. Front. Mol. Neurosci. 10, 293 (2017).

14. Uygur A, Lee RT. Mechanisms of cardiac regeneration. Dev. Cell. 36(4), 362-374 (2016). 15. Bergmann O, Bhardwaj RD, Bernard S et al. Evidence for cardiomyocyte renewal in humans. Science 324(5923), 98-102 (2009). 
16. Bergmann O, Zdunek S, Felker A et al. Dynamics of cell generation and turnover in the human heart. Cell 161(7), 1566-1575 (2015).

17. Wang WE, Li L, Xia X et al. Dedifferentiation, proliferation, and redifferentiation of adult mammalian cardiomyocytes after ischemic injury. Circulation 136(9), 834-848 (2017).

18. Porrello ER, Johnson BA, Aurora AB et al. MiR-15 family regulates postnatal mitotic arrest of cardiomyocytes. Circ. Res. 109(6), 670-679 (2011).

19. Paolini P, Pick D, Lapira J et al. Developmental and extracellular matrix-remodeling processes in rosiglitazone-exposed neonatal rat cardiomyocytes. Pharmacogenomics 15(6), 759-774 (2014).

20. Shah RD, Gonzales F, Golez E et al. The antidiabetic agent rosiglitazone upregulates SERCA2 and enhances TNF-alpha- and LPS-induced NF-kappaB-dependent transcription and TNF-alpha-induced IL-6 secretion in ventricular myocytes. Cell. Physiol. Biochem. 15(1-4), 41-50 (2005).

21. Davis-Turak J, Courtney SM, Hazard ES et al. Genomics pipelines and data integration: challenges and opportunities in the research setting. Expert. Rev. Mol. Diagn. 17(3), 225-237 (2017).

22. Love MI, Huber W, Anders S. Moderated estimation of fold change and dispersion for RNA-seq data with DESeq2. Genome Biol. 15(12), 550 (2014).

23. Dobin A, Davis CA, Schlesinger F et al. STAR: ultrafast universal RNA-seq aligner. Bioinformatics 29(1), 15-21 (2013).

24. Anders S, Pyl PT, Huber W. HTSeq - a Python framework to work with high-throughput sequencing data. Bioinformatics 31(2), 166-169 (2015).

25. Benjamini Y, Hochberg Y. Controlling the false discovery rate: a practical and powerful approach to multiple testing. J. Royal Statist. Soc. Series B 57(1), 289-300 (1995).

26. Draghici S, Khatri P, Tarca AL et al. A systems biology approach for pathway level analysis. Genome Res. 17(10), 1537-1545 (2007).

27. Chen J, Bardes EE, Aronow BJ, Jegga AG. ToppGene Suite for gene list enrichment analysis and candidate gene prioritization. Nucleic Acids Res. 37(Suppl. 2), W305-W311 (2009).

28. Grondin CJ, Davis AP, Wiegers TC, Wiegers JA, Mattingly CJ. Accessing an expanded exposure science module at the comparative toxicogenomics database. Environ. Health Perspect. 126(1), 014501 (2018).

29. Peng $Y$, Zeng $Y, X u J$, Huang $X L$, Zhang $W, X u X L$. PPAR-gamma is involved in the protective effect of 2,3,4',5-tetrahydroxystilbene-2-O-beta-D-glucoside against cardiac fibrosis in pressure-overloaded rats. Eur. J. Pharmacol. 791, 105-114 (2016).

30. Zhuang Y, Li T, Zhuang Y et al. Involvement of of IncR-30245 in myocardial infarction induced cardiac fibrosis through peroxisome proliferator-activated receptor- $\gamma$-mediated connective tissue growth factor signalling pathway. Can. J. Cardiol. 35(4), 480-489 (2019). 
31. Komajda M, McMurray JJ, Beck-Nielsen $\mathrm{H}$ et al. Heart failure events with rosiglitazone in Type 2 diabetes: data from the RECORD clinical trial. Eur. Heart J. 31(7), 824-831 (2010).

32. Androulakis IP, Yang E, Almon RR. Analysis of time-series gene expression data: methods, challenges, and opportunities. Annu. Rev. Biomed. Eng. 9, 205-228 (2007).

33. Peng H, Sarwar Z, Yang XP et al. Profibrotic role for interleukin-4 in cardiac remodeling and dysfunction. Hypertension 66(3), 582-589 (2015).

34. Amit $U$, Kain D, Wagner A et al. New role for interleukin-13 receptor alpha1 in myocardial homeostasis and heart failure. J. Am. Heart Assoc. 6(5), (2017).

35. McVicker BL, Bennett RG. Novel anti-fibrotic therapies. Front. Pharmacol. 8, 318 (2017).

36. Cheng D, Gao H, Li W. Long-term risk of rosiglitazone on cardiovascular events -a systematic review and meta-analysis. Endokrynol Pol 69(4), 381-394 (2018).

37. Ghigo A, Li M. Phosphoinositide 3-kinase: friend and foe in cardiovascular disease. Front. Pharmacol. 6, 169 (2015).

38. Ghigo A, Laffargue M, Li M, Hirsch E. PI3K and calcium signaling in cardiovascular disease. Circ. Res. 121(3), 282-292 (2017).

39. Wang X, Guo Z, Ding Z, Mehta JL. Inflammation, autophagy, and apoptosis after myocardial infarction. J. Am. Heart Assoc. 7(9), pii:e008024 (2018).

40. Youbin Z, Yunsheng Y, Zhenya S, Xiaoming Z, Xiaomei T. Tumor necrosis factor-alpha-induced protein 8-like 2 gene overexpression prolongs the survival of rat allogeneic heart allografts. Transplant. Proc. 47(8), 2517-2522 (2015).

41. Liu ZM, Chen GG, Vlantis AC, Tse GM, Shum CK, van Hasselt CA. Calcium-mediated activation of PI3K and p53 leads to apoptosis in thyroid carcinoma cells. Cell. Mol. Life Sci. 64(11), 1428-1436 (2007).

42. Liao $Y$, Wei $Y$, Zhou $X$ et al. Peptidyl-prolyl cis/trans isomerase Pin1 is critical for the regulation of PKB/Akt stability and activation phosphorylation. Oncogene 28(26), 2436-2445 (2009).

43. Sharova LV, Sharov AA, Nedorezov T, Piao Y, Shaik N, Ko MS. Database for mRNA half-life of 19 977 genes obtained by DNA microarray analysis of pluripotent and differentiating mouse embryonic stem cells. DNA Res. 16(1), 45-58 (2009).

44. Bravo R, Parra V, Gatica D et al. Endoplasmic reticulum and the unfolded protein response: dynamics and metabolic integration. Int. Rev. Cell. Mol. Biol. 301, 215-290 (2013).

45. Brostrom MA, Brostrom CO. Calcium dynamics and endoplasmic reticular function in the regulation of protein synthesis: implications for cell growth and adaptability. Cell Calcium $34(4-5)$, 345-363 (2003). 
46. Gavazzoni M, Vizzardi E, Gorga E et al. Mechanism of cardiovascular toxicity by proteasome inhibitors: new paradigm derived from clinical and pre-clinical evidence. Eur. J. Pharmacol. 828, 8088 (2018).

47. Patel M, Majetschak M. Distribution and interrelationship of ubiquitin proteasome pathway component activities and ubiquitin pools in various porcine tissues. Physiol. Res. 56(3), 341 (2007). 48. Wang X, Robbins J. Heart failure and protein quality control. Circ. Res. 99(12), 1315-1328 (2006). 49. Drevytska T, Gonchar E, Okhai I et al. The protective effect of Hif3a RNA interference and HIFprolyl hydroxylase inhibition on cardiomyocytes under anoxia-reoxygenation. Life Sci.202, 131-139 (2018).

50. Jankowski M, Broderick TL, Gutkowska J. Oxytocin and cardioprotection in diabetes and obesity. BMC Endocr. Disord. 16(1), 34 (2016).

51. Cheng HM, Wang JJ, Chen $\mathrm{CH}$. The role of vascular calcification in heart failure and cognitive decline. Pulse (Basel) 5(1-4), 144-153 (2018).

52. Doherty TM, Uzui H, Fitzpatrick LA et al. Rationale for the role of osteoclast-like cells in arterial calcification. FASEB J. 16(6), 577-582 (2002).

53. Zordoky BN, El-Kadi AO. Modulation of cardiac and hepatic cytochrome P450 enzymes during heart failure. Curr. Drug Metab. 9(2), 122-128 (2008).

54. Sukonina V, Lookene A, Olivecrona T, Olivecrona G. Angiopoietin-like protein 4 converts lipoprotein lipase to inactive monomers and modulates lipase activity in adipose tissue. Proc. Natl Acad. Sci. USA 103(46), 17450-17455 (2006).

55. Augustus AS, Buchanan J, Park TS et al. Loss of lipoprotein lipase-derived fatty acids leads to increased cardiac glucose metabolism and heart dysfunction. J. Biol. Chem. 281(13), 8716-8723 (2006).

56. Yu X, Burgess SC, Ge H et al. Inhibition of cardiac lipoprotein utilization by transgenic overexpression of Angpt|4 in the heart. Proc. Natl Acad. Sci. USA 102(5), 1767-1772 (2005). 57. Ross D, Siegel D. NQO1 in protection against oxidative stress. Curr. Opin. Toxicol. 7, 67-72 (2018).

58. Supruniuk E, Miklosz A, Chabowski A. The implication of PGC-1 - $\alpha$ on fatty acid transport across plasma and mitochondrial membranes in the insulin sensitive tissues. Front. Physiol 8, 923-923 (2017).

59. D'Errico I, Salvatore L, Murzilli S et al. Peroxisome proliferator-activated receptor- $\gamma$ coactivator 1$\alpha(\mathrm{PGC1} \alpha)$ is a metabolic regulator of intestinal epithelial cell fate. Proc. Natl Acad. Sci. USA 108(16), 6603-6608 (2011). 


\section{Figures}

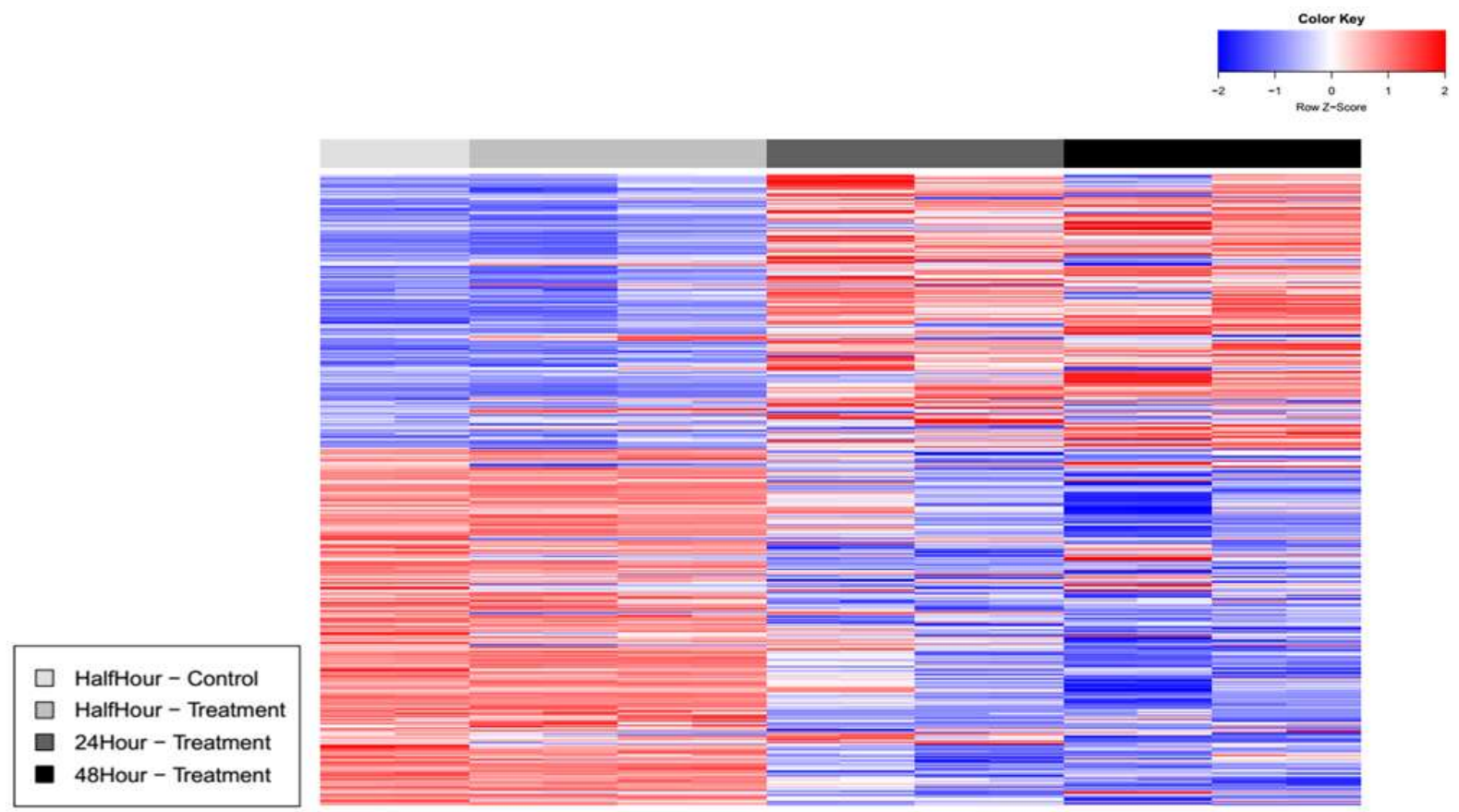

Figure 1. Time course analysis of previously characterized rosiglitazone impacted genes as determined by querying the Comparative Toxicogenomics Database. Only genes differentially expressed in at least one of the comparisons (i.e., $0.5 \mathrm{~h}$ treatment vs $0.5 \mathrm{~h}$ control; $24 \mathrm{~h}$ treatment vs $0.5 \mathrm{~h}$ treatment; $48 \mathrm{~h}$ treatment vs $24 \mathrm{~h}$ treatment) were included, in other words, 758 in total. Red and blue boxes indicate relative over- and underexpression with respect to a reference which is calculated as the mid-point between all groups. For the $0.5 \mathrm{~h}$ control, two technical replicates were included. For each other time point and condition, two independent biological and two technical replicates of each biological control were included (four total replicates). 


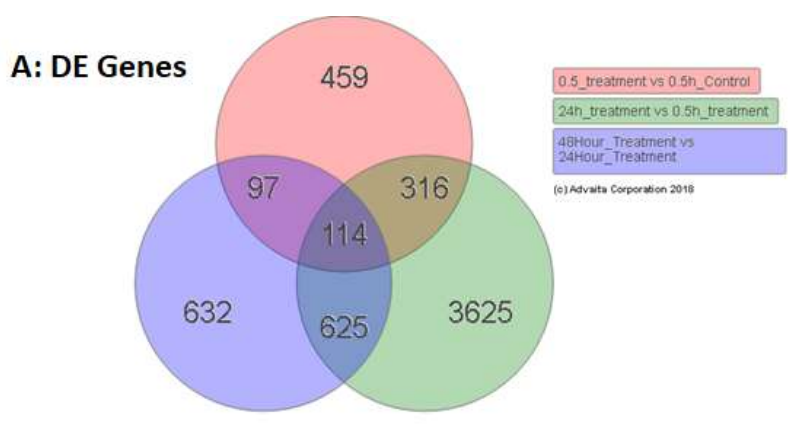

B: Top $10 \mathrm{GO}$ terms enriched $30 \mathrm{~min}$ after treatment which remain continuously activated.

Biological Process

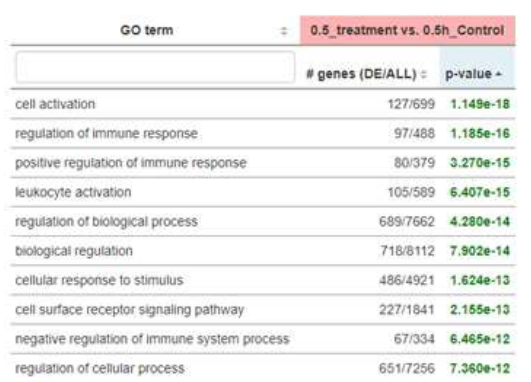

Molecular Function

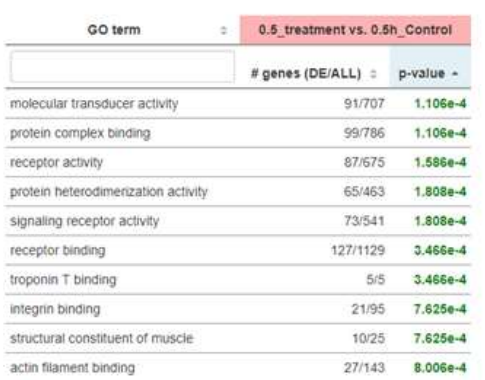

Cellular Component

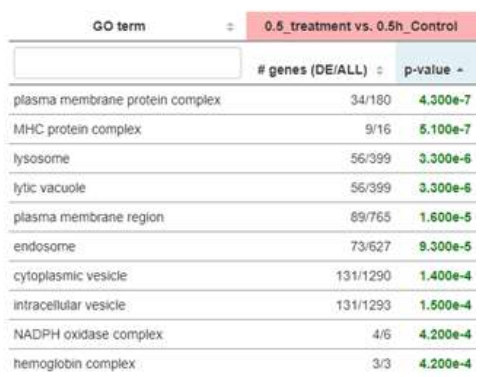

Figure 2. Time course analysis of all differentially expressed genes. (A) Venn diagram showing overlap of significant differentially expressed genes $(q=0.01)$ across the time-course comparisons (i.e., $0.5 \mathrm{~h}$ treatment vs $0.5 \mathrm{~h}$ control; $24 \mathrm{~h}$ treatment vs $0.5 \mathrm{~h}$ treatment; $48 \mathrm{~h}$ treatment vs $24 \mathrm{~h}$ treatment) of the entire transcriptome. (B) Gene ontology terms enriched $30 \mathrm{~min}$ after treatment which remain continuously activated $(q=0.05)$. 
A

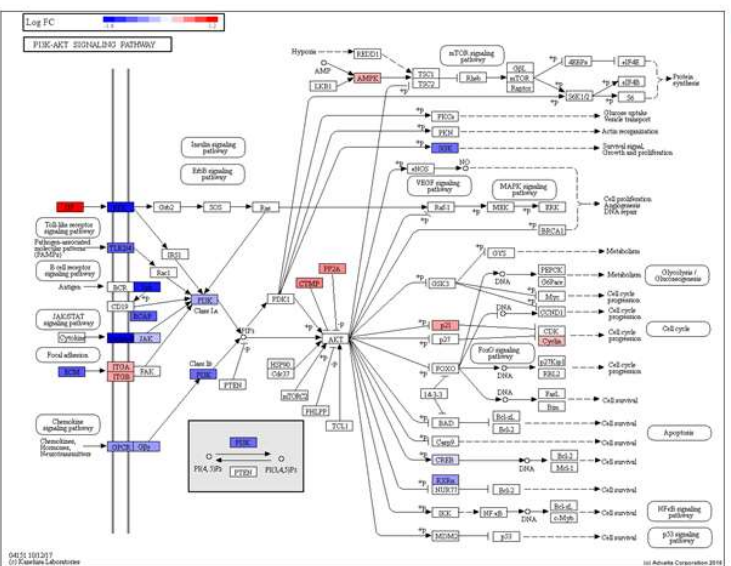

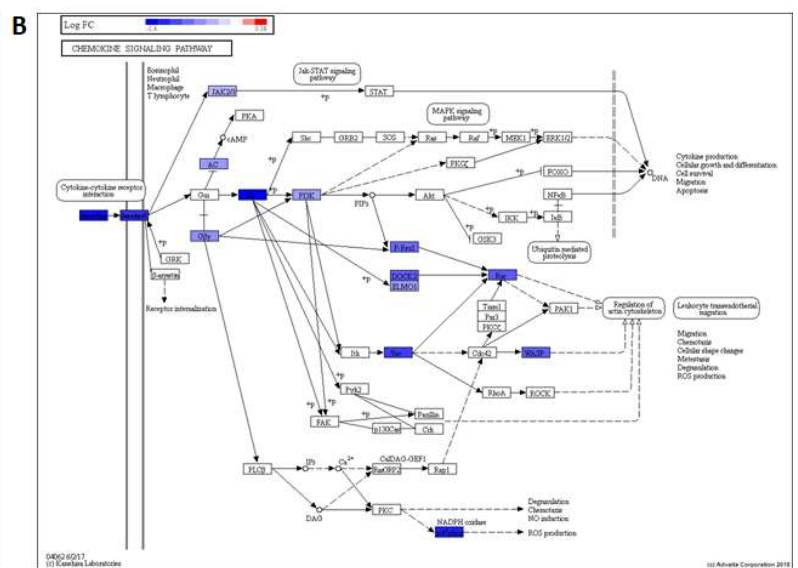

C $49 / 327 \quad 5.5310-5$

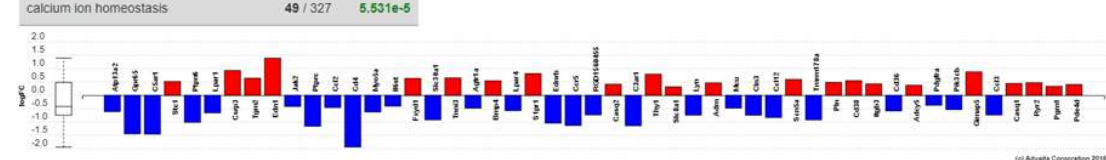

Figure 3. Rosiglitazone treatment versus control at $0.5 \mathrm{~h}$. (A) PI3K-AKT signaling pathway and (B) chemokine signaling pathway showing differentially regulated genes. Red: upregulated; Blue: downregulated in treated NRVMs relative to control. (C) DE genes related to cellular calcium ion homeostasis: upregulated and downregulated transcripts in treated NRVMs relative to control. NRVM: Neonatal rat ventricular myocyte. 

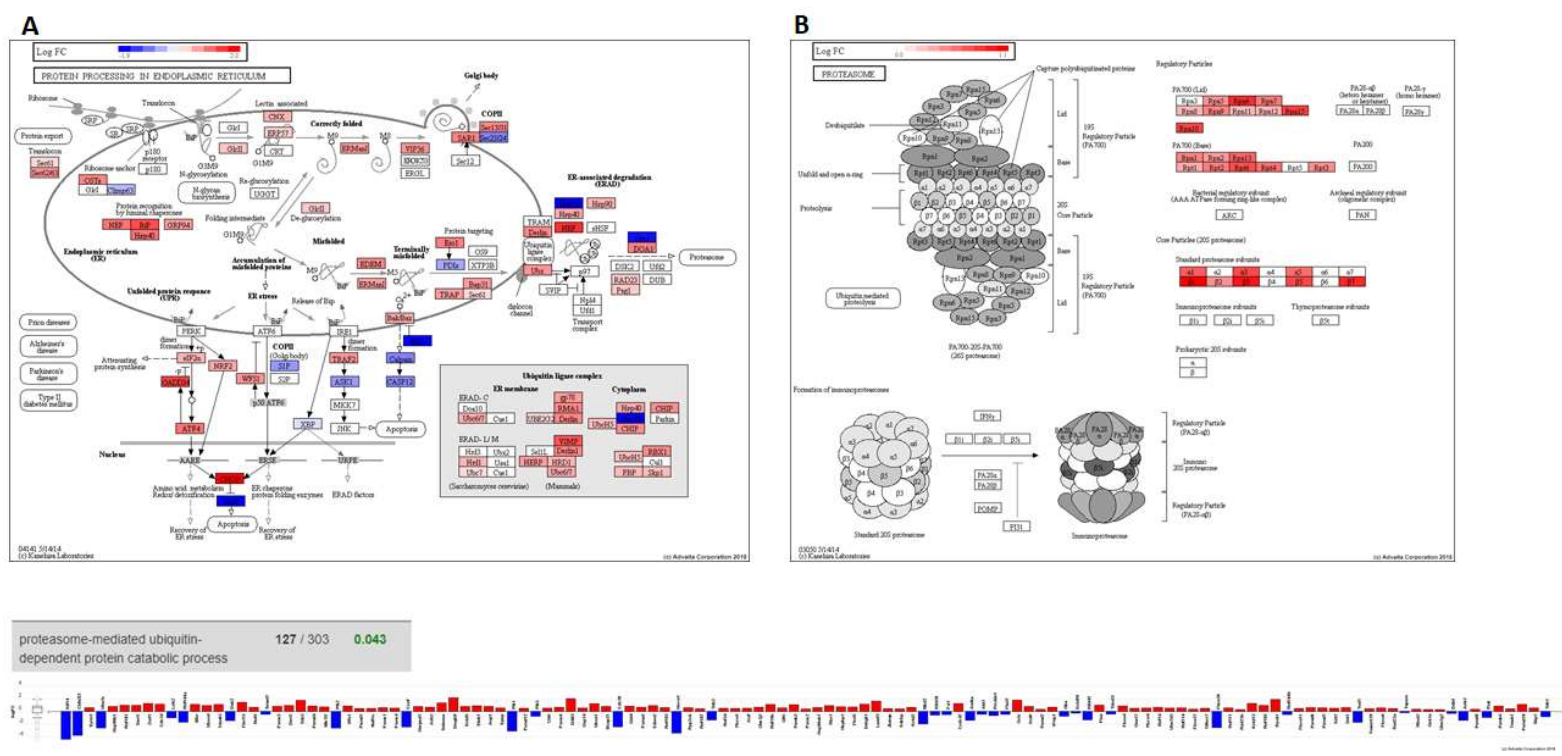

Figure 4. Rosiglitazone treatment at $24 \mathrm{~h}$ versus $0.5 \mathrm{~h}$. (A) Protein processing in endoplasmic reticulum pathway and (B) proteasome showing differentially regulated genes. Red: upregulated; Blue: downregulated at $24 \mathrm{~h}$ relative to the $0.5 \mathrm{~h}$ time point. (C) DE genes related to the proteasomemediated ubiquitin-dependent protein catabolic process $\mathrm{GO}$ term: upregulated and downregulated transcripts at $24 \mathrm{~h}$ relative to the $0.5 \mathrm{~h}$ time point following exposure. GO: Gene ontology. 
A

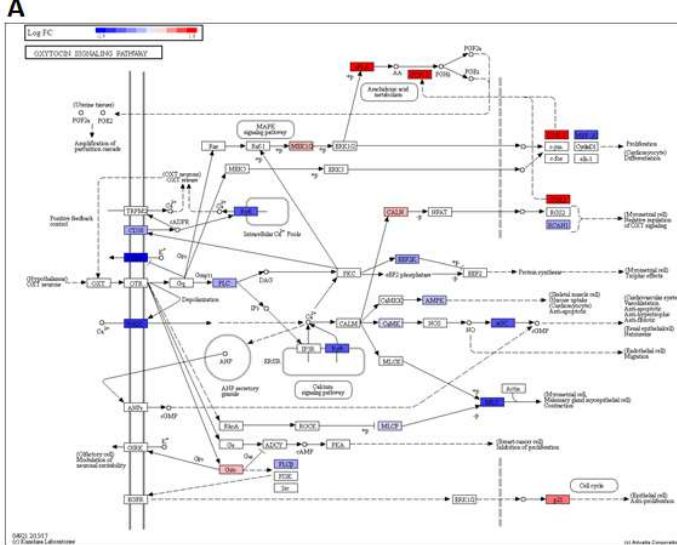

C

B
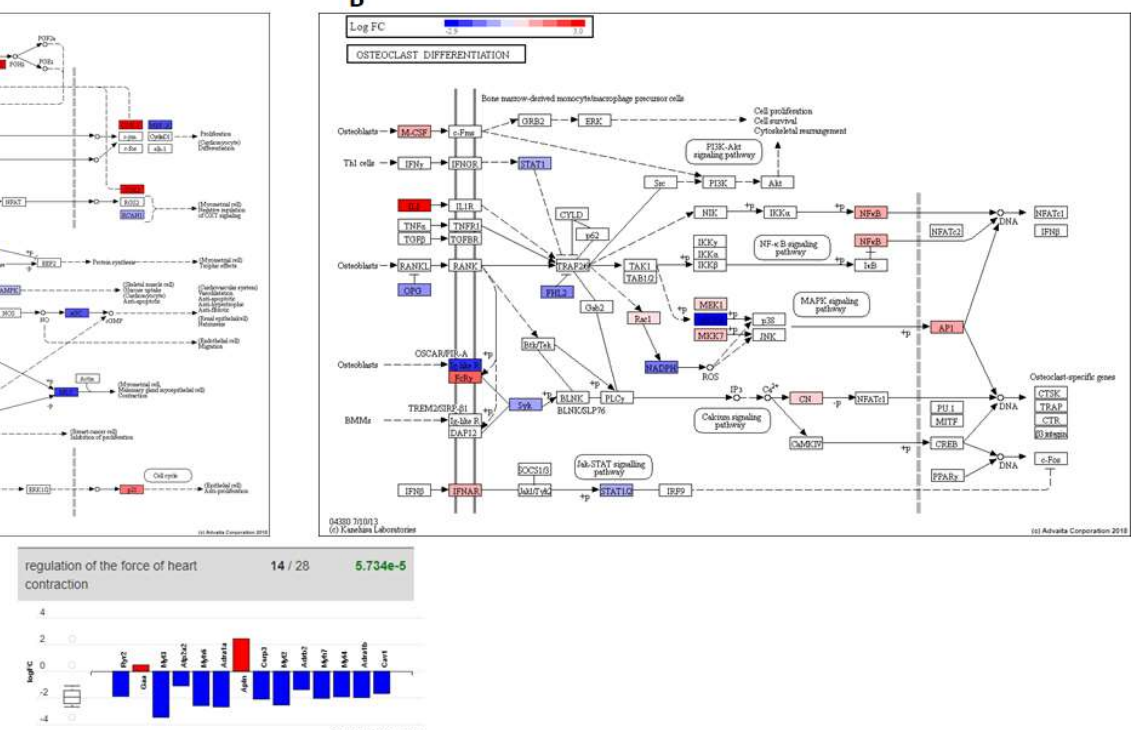

Figure 5. Rosiglitazone treatment at $48 \mathrm{~h}$ versus $24 \mathrm{~h}$. (A) Oxytocin signaling pathway and (B) osteoclast differentiation pathway showing differentially regulated genes. Red: upregulated; Blue: downregulated at the $48 \mathrm{~h}$ time point relative to $24 \mathrm{~h}$. (C) DE genes related to regulation of the force of the heart contraction $\mathrm{GO}$ term: upregulated and downregulated transcripts at $48 \mathrm{~h}$ relative to 24 h. GO: Gene ontology. 
Tables

Table 1. Pathway over-representation analysis using genes listed in the Comparative Toxicogenomics Database that were upregulated by rosiglitazone treatment. The top five most significant pathways are shown.

\begin{tabular}{|c|l|c|c|}
\hline Top & Pathway & Source & q-value FDR B\&H \\
\hline $\mathbf{1}$ & $\begin{array}{l}\text { Fatty acid, triacylglycerol, and ketone } \\
\text { body metabolism }\end{array}$ & Biosystems: REACTOME & $8.21 \mathrm{E}-14$ \\
\hline $\mathbf{2}$ & Metabolism of lipids and lipoproteins & BioSystems: REACTOME & $6.63 \mathrm{E}-13$ \\
\hline $\mathbf{3}$ & PPAR signaling pathway & BioSystems: KEGG & $1.04 \mathrm{E}-09$ \\
\hline $\mathbf{4}$ & Metabolic pathways & Biosystems: KEGG & $4.90 \mathrm{E}-08$ \\
\hline $\mathbf{5}$ & fatty acid metabolic & Pathway Ontology & $1.88 \mathrm{E}-07$ \\
\hline
\end{tabular}


Table 2. Over-representation analysis of mouse phenotypes using genes listed in the Comparative Toxicogenomics Database that were upregulated by rosiglitazone treatment. The top five most significant mouse phenotypes from the International Mouse Phenotyping Consortium (IMPC) database are shown.

\begin{tabular}{|c|l|c|c|}
\hline Top & Mouse Phenotype & Source & q-value FDR B\&H \\
\hline $\mathbf{1}$ & hepatic steatosis & IMPC & $3.47 \mathrm{E}-09$ \\
\hline $\mathbf{2}$ & abnormal glucose homeostasis & IMPC & $2.54 \mathrm{E}-07$ \\
\hline $\mathbf{3}$ & abnormal enzyme/coenzyme activity & IMPC & $2.54 \mathrm{E}-07$ \\
\hline $\mathbf{4}$ & abnormal liver morphology & IMPC & $2.54 \mathrm{E}-07$ \\
\hline $\mathbf{5}$ & abnormal metabolism & IMPC & $2.83 \mathrm{E}-07$ \\
\hline
\end{tabular}


Table 3. Pathway over-representation analysis using genes listed in the Comparative Toxicogenomics Database that were down regulated by rosiglitazone treatment. The top five most significant pathways are shown.

\begin{tabular}{|c|l|c|c|}
\hline Top & Pathway & Source & q-value FDR B\&H \\
\hline $\mathbf{1}$ & Fluid shear stress and atherosclerosis & BioSystems: KEGG & $5.14 \mathrm{E}-14$ \\
\hline $\mathbf{2}$ & $\begin{array}{l}\text { AGE-RAGE signaling pathway in } \\
\text { diabetic complications }\end{array}$ & BioSystems: KEGG & $5.14 \mathrm{E}-14$ \\
\hline $\mathbf{3}$ & $\begin{array}{l}\text { Ensemble of genes encoding } \\
\text { extracellular matrix and extracellular } \\
\text { matrix-associated proteins }\end{array}$ & MSigDB C2 BIOCARTA (v6.0) & $5.14 \mathrm{E}-14$ \\
\hline $\mathbf{4}$ & Extracellular matrix organization & BioSystems: REACTOME & $5.58 \mathrm{E}-11$ \\
\hline $\mathbf{5}$ & Interleukin-4 and 13 signaling & BioSystems: REACTOME & $8.55 \mathrm{E}-11$ \\
\hline
\end{tabular}


Table 4. Over-representation analysis of mouse phenotypes using genes listed in the Comparative Toxicogenomics Database that were down regulated by rosiglitazone treatment. The top five most significant mouse phenotypes from the International Mouse Phenotyping Consortium (IMPC) database are shown.

\begin{tabular}{|c|l|c|c|}
\hline Top & Mouse Phenotype & Source & q-value FDR B\&H \\
\hline $\mathbf{1}$ & muscle phenotype & IMPC & $1.84 \mathrm{E}-19$ \\
\hline $\mathbf{2}$ & abnormal muscle physiology & IMPC & $1.13 \mathrm{E}-13$ \\
\hline $\mathbf{3}$ & abnormal cardiovascular system physiology & IMPC & $1.58 \mathrm{E}-13$ \\
\hline $\mathbf{4}$ & abnormal blood vessel morphology & IMPC & $1.58 \mathrm{E}-13$ \\
\hline $\mathbf{5}$ & abnormal muscle morphology & IMPC & $3.41 \mathrm{E}-13$ \\
\hline
\end{tabular}




\section{Supplemental Tables}

Supplemental Table 1. Differentially expressed genes in at least one of the comparisons (i.e. $0.5 \mathrm{~h}$ treatment vs $0.5 \mathrm{~h}$ control; $24 \mathrm{~h}$ treatment vs $0.5 \mathrm{~h}$ treatment; $48 \mathrm{~h}$ treatment vs $24 \mathrm{~h}$ treatment) which overlap with genes known to be affected by rosiglitazone treatment as obtained from the Comparative Toxicogenomics Database.

\section{Supplemental Table 2.}

Temporal gene expression analysis using ToppGene of over-represented terms in the up-regulated genes from the three time points following rosiglitazone exposure that overlap with genes known to be affected by rosiglitazone treatment as determined from the Comparative Toxicogenomics Database.

\section{Supplemental Table 3.}

Temporal gene expression using ToppGene of over-represented terms in the down-regulated genes from the three time points following rosiglitazone exposure that overlap with genes known to be affected by rosiglitazone treatment as determined from the Comparative Toxicogenomics Database.

Supplemental Table 4. Differentially expressed genes in the early, medium and late time points following exposure to rosiglitazone. The gene ID, gene Symbol, log2 fold-change (logfc) and adjusted p-value or q-value (adjpv) from the DEseq2 analyses are provided. 
Supplemental Table 5. Temporal gene expression analysis of Impacted Gene Ontology - Biological Process terms for the early, medium and late time points following exposure to rosiglitazone. Gene Names, Gene Ontology ID (GO_ID), numbers of differentially expressed genes that belong to a given GO_ID (countDE), total number of genes that belong to a given GO_ID (countAll) and the adjusted pvalue ( $\left.p v_{-} f d r\right)$ are provided for all three time points.

Supplemental Table 6. Temporal gene expression analysis - Molecular Function terms for early, medium and late time points following exposure to rosiglitazone. Gene Names, Gene Ontology ID (GO_ID), numbers of differentially expressed genes that belong to a given GO_ID (countDE), total number of genes that belong to a given GO_ID (countAll) and the adjusted $p$-value ( $p$ _fdr) are provided for all three time points.

Supplemental Table 7. Temporal gene expression analysis - Cellular Component terms for early, medium and late time points following exposure to rosiglitazone. Gene Names, Gene Ontology ID (GO_ID), numbers of differentially expressed genes that belong to a given GO_ID (countDE), total number of genes that belong to a given GO_ID (countAll) and the adjusted p-value ( $p$ _ffr) are provided for all three time points.

Supplemental Table 8. Temporal gene expression analysis of Impacted KEGG pathways for early, medium and late time points following exposure to rosiglitazone. The adjusted $p$-values ( $\left.p v \_f d r\right)$ are provided for all three time points. 